\title{
Erratum to: Effectiveness, Adverse Effects and Drug Compliance of Long-Acting Injectable Risperidone in Children and Adolescents
}

\author{
Mehmet Fatih Ceylan $^{1} \cdot$ Betül Erdogan $^{1} \cdot$ Selma Tural Hesapcioglu ${ }^{1} \cdot$ \\ Esra Cop $^{2}$
}

Published online: 5 September 2017

(c) Springer International Publishing AG 2017

\section{Erratum to: Clin Drug Investig DOI 10.1007/s40261-017-0555-7}

In the original publication, the text in the abstract, methods section was incorrectly published as "In total, 42 patients (age range 12-17 years) who were non-adherent to oral antipsychotic drugs, received $25 \mathrm{mg} /$ day of LAIR intramuscularly every 2 weeks".

The correct text should read as "In total, 42 patients (age range 12-17 years) who were non-adherent to oral antipsychotic drugs, received $25 \mathrm{mg}$ of LAIR intramuscularly every 2 weeks".

The original article was corrected.

The online version of the original article can be found under doi:10.1007/s40261-017-0555-7.

Mehmet Fatih Ceylan

mehmetfceylan@yahoo.com

1 Child and Adolescent Psychiatry Department, Ankara

Yildirim Beyazit University Faculty of Medicine, Ankara,

Turkey

2 Child and Adolescent Psychiatry Department, Ankara

Pediatric and Pediatric Hematology Oncology Training and

Research Hospital, Ankara, Turkey 